\title{
The Impact of Village Poultry Technology Adoption on the Livelihood of Smallholder Farmers in Central Oromia Region, Ethiopia
}

\author{
Ermias T.Tsadik ${ }^{1} \quad$ Berhan Tamir $^{1} \quad$ Zemelak Sahile $^{1}$ \\ 1.Addis Ababa University, College of Veterinary Medicines and Agriculture, PO box 34, Debrezeit, Ethiopia \\ 2.Debrezeit Agricultural Research Centre, PO box 32, Debrezeit, Ethiopia
}

\begin{abstract}
The study was conducted to assess the impact of village poultry technology adoption on smallholder farmers in central Oromia Region, Ethiopia.Using multi-stage random sampling method, 180 technology participants were selected for face to face interview. Structured questionnaire was employed to collect data. Propensity score matching (PSM) Logit model was used to test the impact of the technology. The study revealed that adopters were significantly benefited by $68.5 \%$ from the technology and could produce 101 more eggs per/layer, consumed 18 more eggs/year and got 168.65 Birr more income per layer/year as compared to non-adopters. In conclusion, improved chicken breeds intervention had positive impact on average treatment effect on treated (ATT) and average treatment effect (ATE) on study population. Except livelihood change, the significant differences between adopters and non-adopters on outcome variables were not due to hidden bias but due to the treatment effect of technology intervention.
\end{abstract}

Keywords: Adoption, Impact, Propensity score matching, Village poultry technology

\section{Introduction}

Measuring impact is important in providing essential tools to evaluate systematically the relative efficacy of various types of interventions but there are no 'gold standards' for measuring many interventions impact (Catley et al. 2008). However, a well designed impact assessment can capture the real impact of interventions, be they are positive or negative, intended or unintended on the livelihood of the participants. Successful adoption of improved agricultural technologies could stimulate overall economic growth through inter-sectoral linkages (Sanchez et al. 2009) and it has a significant positive impact on farmers' integration to output market (Asfaw et al. 2010). For instant, in rural areas of Bangladesh, agricultural technologies adoption has robust and positive impact on poverty reduction and on well-being of the households' (Mendola 2007).

In Africa, adoptions of improved agricultural technologies had positive impacts on income, food security and poverty reduction (Asfaw et al. 2010; Wanyama et al. 2010). In Ethiopian condition, adoptions of improved agricultural technologies have positively and significantly affected household's food security (Ferede et al. 2003). For instance, adoption of improved chickpea varieties has a positive and vigorous effect on market and reduces food insecurity of adopter households (Asfaw et al. 2010). Similarly, in Southeastern part of Ethiopia, adoption of improved wheat technologies has a robust and positive effect on farmers' food consumption per adult equivalent per day (Mulugeta \& Hundie 2012). To improve village poultry production, Ethiopian Ministry of Agriculture and Rural Development developed and disseminated village poultry technology (improved chicken breeds). Many households were participated on the technology; however, the impact of the technology intervention was not efficiently assessed in different agro-ecological zones of the country as other agricultural technologies. Therefore, this study was conducted to assess the impact of the village poultry technology adoption on participant smallholder farmers in central Oromia Region, Ethiopia.

\section{Materials and Methods}

\subsection{Description of the study areas}

The study was conducted in the central part of Oromia Region located between $3^{\circ} 24^{\prime} 20^{\prime \prime}$ to $10^{\circ} 23^{\prime} 26^{\prime \prime} \mathrm{N}$ latitudes and $34^{\circ} 07^{\prime} 37^{\prime \prime}$ to $42^{\circ} 58^{\prime} 51^{\prime \prime} \mathrm{E}$ longitudes (OBoFED 2008). The region is characterized by vast geographical and climatic diversity having three major climatic categories called dry, tropical rainy and temperate rainy climates. Three districts, namely Wolmera, Ade'a and Boset were selected based on agro-ecology and history of village poultry technology package distribution.

\subsection{Sampling procedures and data collection}

Three districts Wolmera (highland), Ade'a (mid-altitude) and Boset (lowland) were purposely selected based on their agro-ecology and village poultry technology intervention (CSA 2012). From each district, 5 Kebeles (farmers' administrations) were randomly selected; and using multi-stage random sampling method, 180 technology participants (73 adopters and 107 non-adopters) were selected from participant lists (12 participants per Kebele). Structured questionnaire was used for face to face interview. The questionnaire was pre-tested and 
adjusted prior to the actual survey. The data collection focused on benefit from the technology, impact of the technology on knowledge and skill improvement, livelihood change, egg production change (difference of eggs produced per layer/year after and before participation), egg consumption change (difference of eggs used for family consumption per year after and before participation) and income change (difference of income per layer/year after and before participation).

Variables definition

Table 1. Variables types and their definition

\begin{tabular}{|c|c|c|}
\hline Variable type & Abbreviation & Variable definition \\
\hline Treatment variable & CHICKADO & Adopted improved chicken breeds $(0=\mathrm{No}, 1=\mathrm{Yes})$ \\
\hline \multirow[t]{11}{*}{ Covariates } & SEX & Sex of the respondent $(0=$ Male, $1=$ Female $)$ \\
\hline & AGE & Age of the respondent (years) \\
\hline & FAMSIZE & Family size of the respondent (number) \\
\hline & LANDHOLD & Landholding of the respondent (hectare) \\
\hline & CHCKFEXP & Chicken farming experience of the respondent (years) \\
\hline & TECHEXPI & Technology experience $(0=\mathrm{Up}$ to 5 years, $1=>5$ years $)$ \\
\hline & FRETECH & Frequency of technology received $(0=$ Once, $1=>$ twice $)$ \\
\hline & EXTSERVI & Did you get extension services? $(0=\mathrm{No}, 1=\mathrm{Yes})$ \\
\hline & HLTHSERV & Did you get healthcare services? $(\mathrm{No}=0,1=$ Yes $)$ \\
\hline & TRAINING & Did you get training the technology? $(0=\mathrm{No}, 1=\mathrm{Yes})$ \\
\hline & MARKETDS & How far the town market from your farm? $(\mathrm{km})$ \\
\hline \multirow[t]{6}{*}{ Outcome variables } & KNOWSKIL & Technology improved knowledge and skill? $(0=$ No, $1=$ Yes $)$ \\
\hline & BENEFIT & Did you benefit from the technology? $(0=$ No, $1=$ Yes $)$ \\
\hline & LIVEHOOD & Technology brings positive changes on livelihood? $(0=$ No, $1=$ Yes $)$ \\
\hline & EGGPRO & Change of egg production per layer/year (number) \\
\hline & EGGCONS & Change of egg consumption for family per year (number) \\
\hline & INCOME & Income change per hen per year (Birr) \\
\hline
\end{tabular}

\subsection{Theoretical framework}

This study hypothesized that village poultry technology (improved chicken breeds) adoption has a positive impact on the livelihood of technology participants. According to AIEI (2013), impact evaluation designs can be non-experimental to compare the outcomes of the technology between the treated and control groups. Since this study observational study, non-experimental impact evaluation design was used to analyze the data using propensity scores matching (PSM) method (Rosenbaum \& Rubin 1983). According to Caliendo \& Kopeinig (2005), propensity score is the probability of the participants for observed characteristic X. Propensity score matching method compares average outcomes of the adopters and non-adopters based on estimated propensity score values. If technology was randomly assigned to farmers, the causal effect of technology adoption can be assessed by comparing the difference of variables between treated and untreated, however, the technology is rarely randomly assigned in non-experimental studies which results self-selection bias (Wu et al. 2010). When treatments were not randomly assigned, it was difficult to determine casual inferences whether the difference in outcome between the treated and control groups was due to the treatment effect or other characteristics. The PSM method can estimate average treatment effect of the technology adoption (Caliendo \& Kopeinig 2005).

\subsection{Statistical analysis}

To assess impact of technology adoption, 11 covariates were used. Prior to the analysis, variance inflation factor (VIF) test for continuous variables and contingency coefficient (CC) test for discrete variables were conducted to check whether there is multi-collinearty problem existed among the covariates according to (Gujarati 2004; Berhanu 2012). Similarly, whether there is problem of hetroscedasticity among the covariates, BreuschPagan/Cook-Weisberg "hottest" test was carried out according to (Wooldridge 2002). Generalized linear model (GLM) mean procedure and frequency analyses were used to analyze the socio-economic characteristics of the respondents using SAS version 9.0 software packages. Propensity score "pscore" command of STATA version 12.0 software packages was used to estimate the p-scores. Propensity score matching "psmatch2" command was used to assess the impact of technology adoption on the livelihood of smallholder farmers. For sensitivity analysis "rbounds" bounding approach was used to check wither there is hidden bias due to unobservable variables.

\subsubsection{Econometric model}

\section{Estimation of propensity scores}

According to Caliendo \& Kopeinig (2005), in the implementation of PSM five steps are required. These are pscores estimation, choosing matching algorithm, checking for common support, matching quality/effect 
estimation and sensitivity analysis. Logit model was used to estimate propensity scores (pscores). To solve selfselection problem, PSM method was used as the conditional probability of receiving a treatment (adoption) of observed characteristics (Rosenbaum \& Rubin 1983). Then the treated (adopted) groups were matched with nontreated (non-adopted) groups on the basis of pscores and the average effect of the technology was calculated as the mean difference in outcome of the two groups. The analytical framework 'treatment effect' for individual was defined as the difference between farmer adopted the technology $T_{i}=1$ and not, $T_{i}=0$ as follows:

$$
\mathcal{T}_{i}=Y_{i}(1)-Y_{i}(0)
$$

Where $\mathcal{T}_{i}$ was treatment effect, $\mathrm{Y}_{\mathrm{i}}$ was the outcome on a participant $\mathrm{i}$, whether a participant $\mathrm{T}_{\mathrm{i}}$ had adopted village poultry technology or not.

Since both $Y_{i}(T=1)$ and $Y_{i}(T=0)$ couldn't be observed at the same time on the same participant, there was counterfactual outcome. Due to this, estimating individual treatment effect $\mathcal{J}_{i}$ was not possible. For this shifting to estimating the average treatment effects of the population was required. Based on this, the average treatment effect on the treated ( $\mathcal{T}_{A T T}$ ) was defined as:

$$
\mathcal{T}_{A T T}=E(\mathcal{T} \mid T=1)=E[Y(1) \mid T=1]-E[Y(0) \mid T=1]
$$

And average treatment effect (ATE) of the overall population was defined as the difference between average treatment effect of adopters and non-adopters as follows:

$$
\mathcal{J}_{A T T}=E[Y(1)-Y(0)]
$$

However, in observational study since the treatment was not assigned randomly, there was self-selection bias. To solve this self-selection bias, ATT could be denoted as:

$$
E[Y(1) \mid T=1]-E[Y(0) \mid T=0]=\mathcal{T}_{A T T}+E[Y(0) \mid T=1]-E[Y(0) \mid T=0] .
$$

And the true parameter $\mathcal{T}_{A T T}$ was only identified if and only if there was no self-selection bias. According to Caliendo \& Kopeinig (2005), to solve self-selection bias, conditional independence assumption (CIA) and common support assumptions were used. Where in CIA a set of observable covariates $X$ were not affected by the treatment assignment and the potential outcomes were independent of treatment assignment defined as:

$$
Y(0), Y(1) \amalg T \mid X, \forall X
$$

Where Џdenoted independence

This implies selection was only based on observable characteristics and all variables that influenced treatment assignment and potential outcomes were simultaneously observed. According to Rosenbaum \& Rubin (1983) balancing scores, if potential outcomes are independent of treatment conditional covariates X, they are also independent of treatment conditional on balancing score $b(X)$. Therefore, based on the probability of propensity score, CIA could be defined as:

$$
Y(0), Y(1) \amalg T \mid P(X), \forall X
$$

Where $\mathrm{P}$ and $\forall$ denoted probability and for both groups, respectively

In common support assumption was checking overlaps and identification of common support region for both adopters and non-adopters. The common support condition requires the existence of sufficient overlap in the characteristics of the adopter and non-adopter units to find adequate matches (Mulugeta \& Hundie 2012). Since common support condition was one of the further required for perfect predictability of treatment for a given covariate $\mathrm{X}$, it was defined as:

$$
0<P(T)=1 \mid X<1
$$

By considering CIA and common support assumptions, the PSM estimator for ATT was the mean difference in outcomes over the common support (p-score distribution) expressed as:

$$
\mathcal{T}_{A T T}^{P S M}=E_{P}(X) \mid T=1\{E[Y(1) \mid T=1, P(X)]-E[Y(0) \mid T=0, P(X)]\}
$$

Where $\mathrm{P}(\mathrm{X})$ was the propensity score computed on the covariate Xs.

\section{Choosing of matching algorithm}

To choose the best matching algorism calliper radius, nearest neighbour and kernel matching estimators were conducted to match the adopters with non-adopters. All matching estimators compare the outcome of treated individual with outcomes of untreated (Caliendo \& Kopeinig 2005). Therefore, after estimating the probability 
values on the observable covariates, matching was done using selected a matching algorithm based on the available data at hand. Even though different matching algorisms were used, the final decision to choose the appropriate matching estimator was based on balancing test, relatively low pseudo- $\mathrm{R}^{2}$ value and largest matched sample size (Dehejia \& Wahba, 2002).

\section{Checking overlap/common support region}

According to Caliendo \& Kopeinig (2005), in PSM average treatment effect on treated (ATT) and average treatment effect (ATE) on population are only defined in the common support region. The common support region is the region within the minimum and maximum propensity scores of treated (adopters) and control (nonadopters) groups, respectively. Based on this, the common support region for the current study was done by discarding those observations whose pscores were smaller than the minimum and greater than the maximum of both the adopters and non-adopters (comparison groups).

\section{Assessing match quality/effect estimation}

After choosing the best fitted matching estimator, the next procedure in PSM analysis was testing the covariate balance to check the balancing property of the covariates by comparing the significant test difference before and after matching using the selected matching algorism. To check the balance distribution of relevant variables in both the control and treated groups, the before and after covariates matching should be checked (Caliendo \& Kopeinig 2005). This study assessed the matching quality to check the balance distribution the variables. Balance test was conducted to know whether there was significant difference in mean value of per-treatment characteristics of both adopter and non-adopter respondents. According to Rosenbaum \& Rubin (1985) standardized bias (SB) is used to assess the marginal distance of covariates and $t$-test is used to check whether there is a significant difference in covariate means for both groups in the common support region (check matching quality). According to Tolemariam (2010), a matching estimator having insignificant mean differences in all covariates, having low pseudo- $\mathrm{R}^{2}$ value and resulting large matched sample size was preferred as a best matching quality. Since testing the statistical significant of treatment effects and computing their standard errors is not straightforward (Caliendo \& Kopeinig 2005), bootstrapping method (popular method) was used to solve this problem and to compute the standard error for the estimate of the technology impact (Lechner 2002; Mulugeta \& Hundie 2012). Since the matching quality test this study suggests that the chosen matching algorithm was relatively best for the data, estimating the average treatment effect on the treated (ATT) was the next task.

\section{Sensitivity analysis}

Since ATT matched outcome variables estimations show significant, ssensitivity analysis was the final (fifth) step conducted in order to check the robustness of the estimation (whether there were hidden biases affected the estimated ATT or not). Respondents KNOWSKIL improvement ATT t-test shows insignificant, therefore it was not considered in the sensitivity analysis. According to Keele (2010), when outcome indicators showed significant, two things should be done in sensitivity analysis in order to check whether there are hidden biases or not. These are sensitivity analysis on the p-values and see how the p-value increases for increasing values of degree of departure from random assignment of treatment $(\Gamma)$ and how the magnitude of the treatment effect changes with an increasing $\Gamma$ where each sensitivity test is built on a specific randomization test for a type of outcome. Since the lower bounds Hodges-Lehmman point estimates under underestimated the true treatment effect, upper binds were used according to Becker \& Caliendo (2007). Based on CIA, the treatment effect could be estimated with matching estimators on selected observable characteristics. However, unobserved variables which affect assignment to the treatment and the outcome variable simultaneously might result hidden bias called unobserved heterogeneity (Caliendo \& Kopeinig 2005). Since it was not possible to estimate the magnitude of selection bias with non-experimental data, this problem was address using "rbounds" bounding approach proposed by Rosenbaum (2002).

\section{Results}

\subsection{Socio-economic characteristics of the respondents}

In this study, $65.6 \%$ and $34.4 \%$ of the respondents were male and female, respectively. The age of the respondents ranges from 19-74 years with mean of 42 years. The family size ranges from 1-12 with a mean of 6 per household. About $38.9 \%$ of the respondents had nil or less than 1 hectare farmland and most $(65.6 \%)$ of them had less than 2 hectare of farmland. The chicken farming experience ranges 5-58 years with mean of 20.8 years. Most of the respondents (47.8\%) had 16-30 years of chicken keeping experiences. About $46.1 \%$ and $53.9 \%$ of the respondents have up to 5 and over 5 years of village poultry technology package experiences, respectively.

\subsection{Impact of technology adoption}

Variance Inflation Factor (VIF) test for continuous covariates and contingency coefficient test for categorical variables were less than 10 and 0.75, respectively. Similarly, Breusch-Pagan/Cook-Weisberg test for heteroskedasticity among covariates had $\mathrm{p}=0.9754$ which is insignificant. Theses imply that there were no 
multicollinearity and heteroskedasticity problems existed among the covariates thus no variable was dropped from the model.

\subsubsection{Propensity score estimation}

The estimated pscores of the covariates are indicated in Table 1 . The pseudo- $\mathrm{R}^{2}$ value of the estimated model resulted 0.1108 which was fairly low. The pscores estimation show, respondents who were older, had more chicken keeping experience and far from market were less likely to participate on technology. Participation on improved chicken breed technology was positively and significantly influenced by extension $(\mathrm{P}<0.01)$ and training $(\mathrm{P}<0.05)$ services. The logit estimated intercept was $(-0.567)$ negative and insignificant.

Table 1. Estimated of the propensity score for explanatory variables

\begin{tabular}{lcccc}
\hline Variable & Coefficient & SE & Z-value & P-value \\
\hline SEX & 0.292 & 0.359 & 0.81 & 0.416 \\
AGE & -0.027 & 0.025 & -1.10 & 0.272 \\
FAMSIZE & 0.023 & 0.079 & 0.29 & 0.772 \\
LANDHOLD & 0.059 & 0.129 & 0.45 & 0.650 \\
CHCKFEXP & -0.00005 & 0.023 & -0.00 & 0.998 \\
TECHEXPI & 0.180 & 0.362 & 0.50 & 0.620 \\
FRETECH & 0.559 & 0.399 & 1.40 & 0.161 \\
EXTSERVI & 1.063 & 0.352 & $3.02^{* *}$ & 0.003 \\
HLTHSERV & 0.061 & 0.384 & 0.16 & 0.873 \\
TRAINING & 0.730 & 0.350 & $2.09 *$ & 0.037 \\
MARKETDS & -0.029 & 0.024 & -1.22 & 0.223 \\
Constant & -0.567 & 0.930 & -0.61 & 0.542
\end{tabular}

Number of observation $=180 ; \operatorname{LR} \chi^{2}(11)=27.02 ;$ Prob $>\chi^{2}=0.0046 ;$ Pseudo- $R^{2}=0.1108 ;$ Log likelihood $=-$ 108.39801

$* *=\mathrm{p} \leq 0.01, *=\mathrm{p} \leq 0.05$

\subsubsection{Choosing of matching algorithm}

As indicated in Table 2, nearest neighbor 5 (NN 5) matching estimator fulfilled the balancing test (equal means) that indicates all covariates were included in the model and insignificant mean differences between the two groups after matching, had relatively low pseudo- $\mathrm{R}^{2}$ value and resulted largest sample size (matched sample size). Thus, NN (5) was identified the best model fitted matching estimator for this study. In pscore estimation and performing initial balance of the covariate, 4 numbers of blocks were identified that ensured the mean pscore was not different for adopters and non-adopters in each blocks.

Table 2. Matching performance of different estimators

\begin{tabular}{llll}
\hline Matching estimator & \multicolumn{2}{c}{ Performance criteria } \\
\cline { 2 - 4 } & Balance test* & Pseoud-R ${ }^{2}$ & Matched sample size \\
\hline Radius caliper & 11 & 0.068 & 123 \\
0.1 & 11 & 0.080 & 128 \\
0.25 & 11 & 0.078 & 142 \\
0.5 & & & 169 \\
Nearest neighbor & 11 & 0.040 & 169 \\
NN(1) & 11 & 0.020 & 169 \\
NN(2) & 11 & 0.018 & 169 \\
NN(3) & 11 & 0.012 & 169 \\
NN(4) & 11 & 0.008 & 169 \\
NN(5) & & & 169 \\
Kernel & 11 & 0.011 & 169 \\
Band width 0.1 & 10 & 0.049 & 0.072 \\
Band width 0.25 & 9 & & \\
Band width 0.5 & & & \\
\hline
\end{tabular}

*Number of explanatory variables with insignificant mean difference between the matched groups of adopter and non-adopter.

\subsubsection{Common support region}

The estimated pscores ranges from 0.123 to 0.782 with a mean $0.495 \pm 0.17$ for adopters and ranges from 0.105 0.735 for non-adopters with a mean $0.352 \pm 0.17$. By discarding observations whose estimated pscores fall outside, the common support region was identified. Therefore, common support region ranges 0.123 to 0.735 which means households whose estimated pscores less than 0.123 and larger than 0.735 were not considered for the matching purposes. As a result, 11 households ( 3 adopters and 8 non- adopters) were discarded from the analysis. Figure 1 and 2 show the distribution of households with respect to the estimated pscores of the adopters and nonadopters, respectably in the common support condition. As shown in Figures, most of the adopter households 
were distributed in the right side while most of non-adopters households were distributes in the left side. There was wider area in which both the groups had in common where most of the adopters had pcore around 0.6 while majority of the non-adopters had around 0.2 .

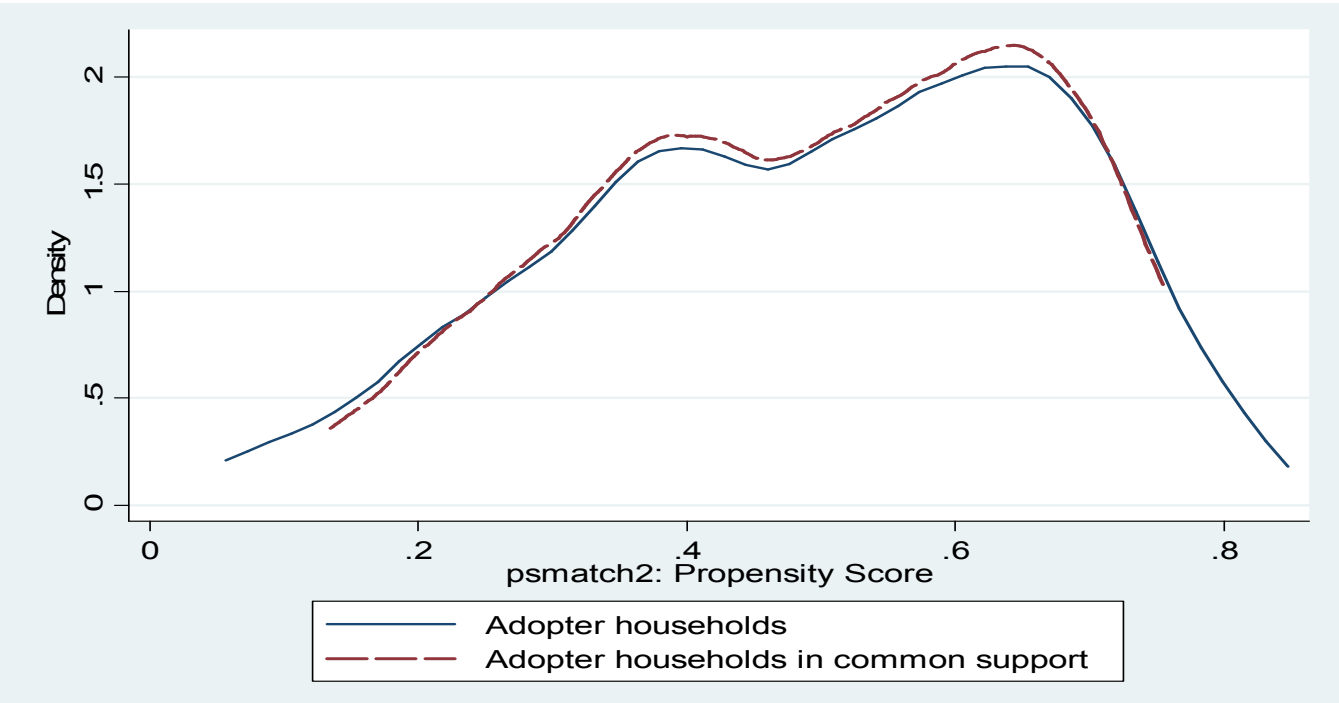

Figure 1. Kernel density of adopter households in the common support region

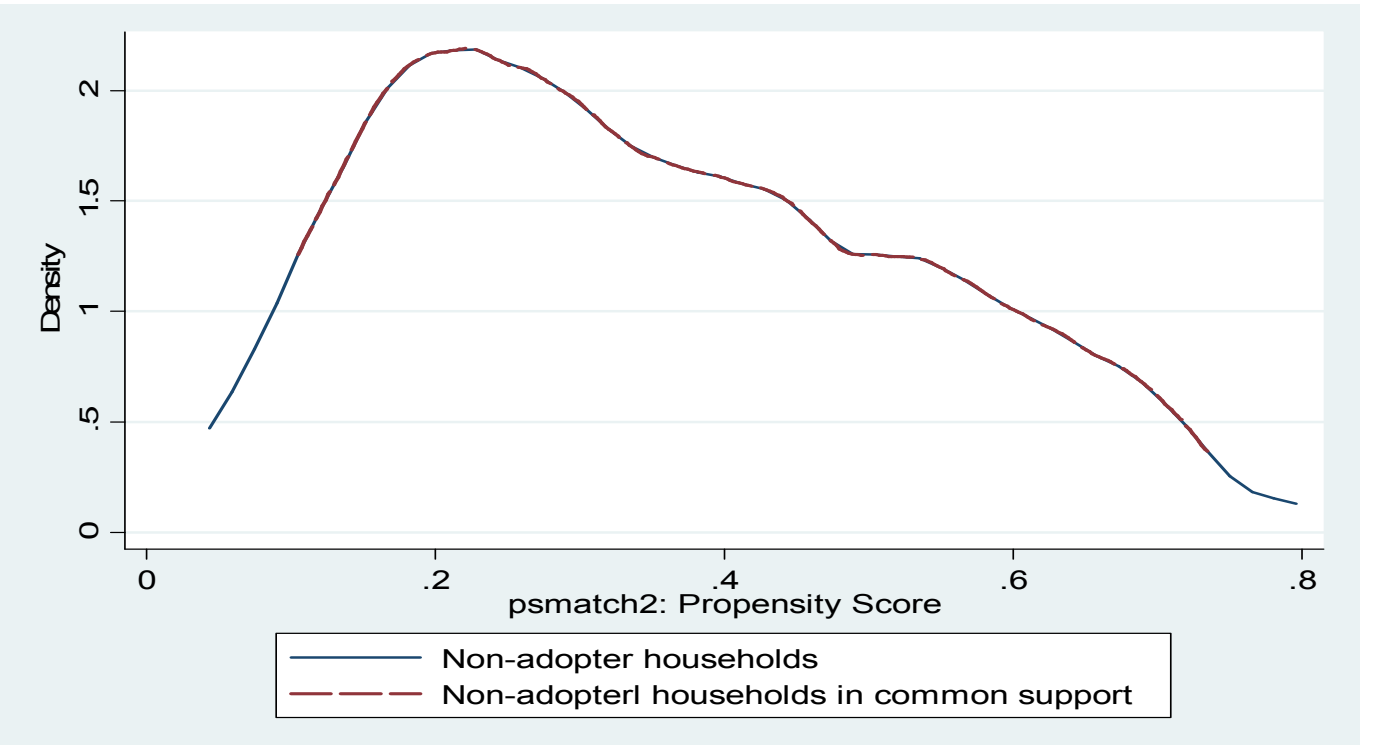

Figure 2. Kernel density of non-adopter households in the common support region

\subsubsection{Matching quality/effect estimation}

Before matching, $27.8 \%$ of the covariates pscore estimates show significant but after matching all show insignificant. The balancing efficiency of the estimator was determined by considering the reduction of the mean SB between the matched and unmatched respondents and equality of means (adopters and non-adopters) was tested using t-test. As shown in Table 3, fifth column shows the mean BS before and after matching while sixth column shows the total mean SB reduction obtained by the matching procedure. The absolute value of unmatched means difference ranges from $4.4-82.6 \%$ and 3 of the covariates $(27.8 \%)$ were significant. However, after they matched, the absolute value of SB reduction ranges from $0.1-9.6 \%$ and the t-test show insignificant with low Pseudo- $R^{2}(0.008)$ that means all covariates were included (balanced) in the model. 
Table 3. Testing of covariates balance for adopters and non-adopters

\begin{tabular}{|c|c|c|c|c|c|c|c|}
\hline \multirow[t]{2}{*}{ Variable } & \multirow{2}{*}{$\begin{array}{l}\text { Unmatched } \\
\text { Matched }\end{array}$} & \multicolumn{2}{|c|}{ Mean } & \multirow[t]{2}{*}{ \%bias } & \multirow{2}{*}{$\begin{array}{l}\text { \%reduction } \\
\text { /bias/ }\end{array}$} & \multicolumn{2}{|c|}{ T-test } \\
\hline & & Treated & Control & & & $\mathrm{T}$ & $\mathrm{P}>/ \mathrm{t} /$ \\
\hline \multirow[t]{2}{*}{ pscore } & Unmatched & 0.495 & 0.352 & 82.6 & & $5.45 * * *$ & 0.000 \\
\hline & Matched & 0.484 & 0.482 & 1.1 & 98.6 & 0.07 & 0.945 \\
\hline \multirow[t]{2}{*}{ SEX } & Unmatched & 0.378 & 0.321 & 12.0 & & 0.80 & 0.426 \\
\hline & Matched & 0.366 & 0.392 & -5.3 & 56.0 & -0.31 & 0.758 \\
\hline \multirow[t]{2}{*}{ AGE } & Unmatched & 41.205 & 42.896 & -16.4 & & -1.08 & 0.281 \\
\hline & Matched & 41.538 & 41.786 & -2.4 & 85.3 & -0.15 & 0.879 \\
\hline \multirow[t]{2}{*}{ FAMSIZE } & Unmatched & 6.068 & 5.962 & 4.4 & & 0.29 & 0.768 \\
\hline & Matched & 6.028 & 6.025 & 0.1 & 97.3 & 0.01 & 0.994 \\
\hline \multirow[t]{2}{*}{ LANDHOLD } & Unmatched & 1.986 & 1.917 & 4.4 & & 0.29 & 0.768 \\
\hline & Matched & 1.985 & 1.913 & 4.6 & -4.6 & 0.27 & 0.784 \\
\hline \multirow[t]{2}{*}{ CHCKFEXP } & Unmatched & 20.108 & 21.245 & -11.3 & & -0.74 & 0.459 \\
\hline & Matched & 20.521 & 19.555 & 9.6 & 15.0 & 0.60 & 0.547 \\
\hline \multirow[t]{2}{*}{ TECHEXPI } & Unmatched & 0.547 & 0.514 & 6.7 & & 0.44 & 0.658 \\
\hline & Matched & 0.521 & 0.482 & 7.9 & 17.2 & 0.47 & 0.641 \\
\hline \multirow[t]{2}{*}{ FRETECH } & Unmatched & 0.770 & 0.623 & 32.3 & & $2.11 *$ & 0.036 \\
\hline & Matched & 0.761 & 0.744 & 3.7 & 88.6 & 0.23 & 0.817 \\
\hline \multirow[t]{2}{*}{ EXTSERVI } & Unmatched & 0.689 & 0.406 & 59.1 & & $3.88 * * *$ & 0.000 \\
\hline & Matched & 0.676 & 0.676 & 0.0 & 100.0 & 0.00 & 1.000 \\
\hline \multirow[t]{2}{*}{ HLTHSERV } & Unmatched & 0.284 & 0.245 & 8.7 & & 0.58 & 0.565 \\
\hline & Matched & 0.282 & 0.296 & -3.2 & 63.4 & -0.18 & 0.854 \\
\hline \multirow[t]{2}{*}{ TRAINING } & Unmatched & 0.721 & 0.500 & 48.3 & & $3.16 * * *$ & 0.002 \\
\hline & Matched & 0.718 & 0.707 & 2.4 & 95.1 & 0.15 & 0.883 \\
\hline \multirow[t]{2}{*}{ MARKETDS } & Unmatched & 11.291 & 12.276 & -14.0 & & -0.92 & 0.356 \\
\hline & Matched & 11.535 & 11.300 & 3.4 & 76.1 & 0.20 & 0.840 \\
\hline
\end{tabular}

$* * *=\mathrm{P} \leq 0.001, *=\mathrm{P} \leq 0.05$

\subsubsection{Estimation of the average treatment effects (ATT)}

The average treatment effect on treated due to improved chicken breeds adoption (CHICKADO) on the outcome variables is indicated on Table 4. As shown, adopters and non-adopters show $73.2 \%$ and $72.7 \%$ knowledge and skill improvement due to the technology intervention but adoption didn't bring significant difference on knowledge and skill (KNOWSKIL) improvement between the adopters and non-adopters. However, technology adoption had significant $(\mathrm{P}<0.001)$ impact on adopters as benefited from the technology (BENEFITD), changes on the livelihood of the household (LIVEHOOD), changes on egg production (CHANGEGG), egg consumption (EGGCONS) and income change (INCOME) as impact indicators. Adopters were significantly benefited from the technology by $68.5 \%$ (difference value/adopters value*100) as compared to non-adopters. Moreover, due to adopting the technology, adopters could produce 101 more eggs per layer/year, consumed 18 more eggs/year and got 168.65 Birr more income per layer/year as compared to non-adopters. The ATT and the overall average treatment effect (ATE) on the study population are indicated in Table 5. As shown in the Table, the ATE of improved chicken breeds intervention on the population increased knowledge and skill by $3.6 \%$, egg production by 97.4 eggs per layer/year, egg consumption by17.2 eggs/household per year and income by 163.05 Birr/layer/year.

Table 4. The ATT of improved chicken breeds intervention on the outcome indicators

\begin{tabular}{llccccc}
\hline Treatment & Outcome & Adopters & Non-adopters & Difference & S.E. $^{\text {bs }}$ & T-stat $^{\text {C }}$ \\
\hline CHICKADO & KNOWSKIL & 0.732 & 0.727 & 0.006 & 0.076 & 0.07 \\
& BENEFITD & 0.958 & 0.301 & 0.656 & 0.126 & $10.62^{* * *}$ \\
& LIVEHOOD & 0.831 & 0.079 & 0.752 & 0.066 & $12.86^{* * *}$ \\
& CHANGEGG & 157.87 & 56.57 & 101.30 & 7.92 & $15.42^{* * *}$ \\
& EGGCONS & 38.04 & 19.91 & 18.13 & 2.81 & $6.61^{* * *}$ \\
& INCOME & 249.74 & 81.09 & 168.65 & 24.18 & $12.04^{* * *}$ \\
\hline
\end{tabular}

$* * *=P \leq 0.001 ;{ }^{b s}$ bootstrapped S.E. obtained for 100 replications 
Table 5. Unmatched and matched average treatment effect of outcome variables

\begin{tabular}{|c|c|c|c|c|c|c|}
\hline Variable & Sample & Treated & Controls & Difference & S.E. & T-stat \\
\hline knowski 1 & $\begin{array}{r}\text { Unmatched } \\
\text { ATT } \\
\text { ATU } \\
\text { ATE }\end{array}$ & $\begin{array}{l}.743243243 \\
.732394366 \\
.591836735\end{array}$ & $\begin{array}{l}.547169811 \\
.726760563 \\
.648979592\end{array}$ & $\begin{array}{l}.196073432 \\
.005633803 \\
.057142857 \\
.035502959\end{array}$ & $\begin{array}{r}.072155868 \\
.084941169 \\
.\end{array}$ & $\begin{array}{r}2.72 \\
0.07 \\
.\end{array}$ \\
\hline Benefitd & $\begin{array}{r}\text { Unmatched } \\
\text { ATT } \\
\text { ATU } \\
\text { ATE }\end{array}$ & $\begin{array}{l}.959459459 \\
.957746479 \\
.204081633\end{array}$ & $\begin{array}{l}198113208 \\
.301408451 \\
.955102041\end{array}$ & $\begin{array}{l}.761346252 \\
.656338028 \\
.751020408 \\
.711242604\end{array}$ & $\begin{array}{r}.050418382 \\
.06178963 \\
.\end{array}$ & $\begin{array}{r}15.10 \\
10.62 \\
.\end{array}$ \\
\hline Livehood & $\begin{array}{r}\text { Unmatched } \\
\text { ATT } \\
\text { ATU } \\
\text { ATE }\end{array}$ & $\begin{array}{l}.837837838 \\
.830985915 \\
.071428571\end{array}$ & $\begin{array}{l}.075471698 \\
.078873239 \\
.797959184\end{array}$ & $\begin{array}{l}.76236614 \\
.752112676 \\
.726530612 \\
.737278107\end{array}$ & $\begin{array}{r}.047430605 \\
.05848412 \\
.\end{array}$ & $\begin{array}{r}16.07 \\
12.86 \\
.\end{array}$ \\
\hline Changegg & $\begin{array}{r}\text { Unmatched } \\
\text { ATT } \\
\text { ATU } \\
\text { ATE }\end{array}$ & $\begin{array}{l}156.337838 \\
157.873239 \\
57.4081633\end{array}$ & $\begin{array}{l}57.0377358 \\
56.5690141 \\
152.004082\end{array}$ & $\begin{array}{r}99.300102 \\
101.304225 \\
94.5959184 \\
97.4142012\end{array}$ & $\begin{array}{r}5.59746435 \\
6.56757751 \\
.\end{array}$ & $\begin{array}{r}17.74 \\
15.42 \\
.\end{array}$ \\
\hline Eggcons & $\begin{array}{r}\text { Unmatched } \\
\text { ATT } \\
\text { ATU } \\
\text { ATE }\end{array}$ & $\begin{array}{r}38.0405405 \\
38.0422535 \\
19\end{array}$ & $\begin{array}{l}19.0188679 \\
19.9098592 \\
35.5510204\end{array}$ & $\begin{array}{l}19.0216726 \\
18.1323944 \\
16.5510204 \\
17.2153846\end{array}$ & $\begin{array}{r}2.24241873 \\
2.74472829 \\
\text {. }\end{array}$ & $\begin{array}{r}8.48 \\
6.61 \\
.\end{array}$ \\
\hline Icome & $\begin{array}{r}\text { Unmatched } \\
\text { ATT } \\
\text { ATU } \\
\text { ATE }\end{array}$ & $\begin{array}{l}245.359459 \\
249.740141 \\
74.1841837\end{array}$ & $\begin{array}{l}73.2853774 \\
81.0860563 \\
233.166122\end{array}$ & $\begin{array}{l}172.074082 \\
168.654085 \\
158.981939 \\
163.045385\end{array}$ & $\begin{array}{r}11.4022165 \\
14.0134593 \\
.\end{array}$ & $\begin{array}{r}15.09 \\
12.04 \\
.\end{array}$ \\
\hline
\end{tabular}

\subsubsection{Sensitivity analysis}

Table 6 shows the result of Rosenbaum sensitivity test for upper bound significance level of improved chicken breed technology participation on outcome variables. Each column shows the critical value of $\Gamma$ which bears statistical difference between treated and control households. As shown in Table, when $\Gamma=1$ (assuming of no hidden bias due to an unobserved confounder), the sensitivity analysis estimated p-values were quite close to estimated $\mathrm{p}$-values $(* * *=\mathrm{p}<0.001)$ of the matching analysis of Table 4 . When $\Gamma$ value increases by 0.5 to $\Gamma=3$, the p-values changes were significant which was below 0.05 (usual threshold).

Table 6. Rosenbaum sensitivity test for upper bound significance level ( $\mathrm{N}=180$ matched pairs)

\begin{tabular}{lccccc}
\hline & \multicolumn{5}{c}{$\Gamma(\mathrm{Gamma})$} \\
\cline { 2 - 5 } Outcome variable & $\Gamma=1$ & $\Gamma=1.5$ & $\Gamma=2$ & $\Gamma=2.5$ & $\Gamma=3$ \\
\hline BENEFITD & 0.000 & $2.4 \mathrm{e}-15$ & $5.9 \mathrm{e}-12$ & $6.5 \mathrm{e}-10$ & $1.5 \mathrm{e}-08$ \\
LIVEHOOD & 0.000 & $4.2 \mathrm{e}-12$ & $1.6 \mathrm{e}-09$ & $6.1 \mathrm{e}-08$ & $6.8 \mathrm{e}-07$ \\
CHANGEGG & 0.000 & 0.000 & $1.1 \mathrm{e}-16$ & $8.8 \mathrm{e}-14$ & $8.9 \mathrm{e}-12$ \\
EGGCONS & 0.000 & 0.000 & $2.2 \mathrm{e}-16$ & $1.5 \mathrm{e}-13$ & $1.4 \mathrm{e}-11$ \\
INCOME & 0.000 & 0.000 & $1.1 \mathrm{e}-16$ & $9.5 \mathrm{e}-14$ & $9.4 \mathrm{e}-12$ \\
\hline
\end{tabular}

$\Gamma=\log$ odds of differential due to unobserved factors; $1,1.5 \ldots$. and 3 are measures of the degree of departure from random assignment of treatment.

Table 7 shows the upper bound Hodges-Lehmman point estimates. Since the lower bounds under underestimated the true treatment effect, upper bound Hodges-Lehmman point estimates were used. As shown in the Table, the median estimates were smaller than the mean estimates differences reported in Table 4. However, except the impact of the treatment on the livelihood changes of the participants, the estimates were slightly more robust and the upper bounds didn't bracket zero. The Hodges-Lehmman point estimates of livelihood changes smaller than the estimated mean difference in Table 4 and shows slightly more robust as $\Gamma$ value of 1.5 before the upper bound brackets zero. If there is no hidden bias, Hodges-Lehmman point estimates was 0.50, however, as $\Gamma$ value increases more than 1.5 , the estimated upper bounds bracket zero that implies there was possible hidden bias due to an unobserved confounder on LIVEHOOD. 
Table 7. Rosenbaum upper bound sensitivity test for Hodges-Lehmann point estimate Outcome variable $\Gamma($ Gamma $)$

\begin{tabular}{lccccc} 
& $\Gamma=1$ & $\Gamma=1.5$ & $\Gamma=2$ & $\Gamma=2.5$ & $\Gamma=3$ \\
\hline BENEFITD & 0.50 & 0.50 & 0.50 & 0.50 & 0.50 \\
LIVEHOOD & 0.50 & 0.50 & $-3.7 \mathrm{e}-07$ & $-3.7 \mathrm{e}-07$ & $-3.7 \mathrm{e}-07$ \\
CHANGEGG & 95 & 77.5 & 65 & 60 & 57.5 \\
EGGCONS & 25 & 23 & 22 & 20 & 19 \\
INCOME & 130 & 107.8 & 94.5 & 85.75 & 79 \\
\hline
\end{tabular}

*Hodges-Lehmann point estimates are upper bound estimates; $\Gamma=\log$ odds of differential due to unobserved factors; $1,1.5 \ldots$ and 3 are measures of the degree of departure from random assignment of treatment.

\section{Discussion}

The estimated model pseudo- $\mathrm{R}^{2}$ of the current study was fairly low $(0.1108)$. This indicates the covariates were well fitted with the model. In agreement, Caliendo \& Kopeinig (2008) and Pradhan \& Rawlings (2002) revealed that low pseudo- $R^{2}$ value indicates that the allocation of the treatment has been fairly random and the result suggests that treatment households do not have diverse characteristics over all and hence obtaining a good match between treatment and control households. The coefficient of pscore estimated for age, chicken keeping experience and market distance show negative values. These indicate, older farmers were reluctant to participate on the technology, more chicken keeping experience doesn't mean farmers could participate on the technology and as market become distance from the farmers homestead, the likelihood of their participation on the technology become less. Participation on improved chicken breed technology was positively and significantly influenced by extension and training services. These imply, as the respondents get better extension and training services, the probability their participation on improved chicken breed technology increases too. The logit estimated intercept of the current study was negative and insignificant. This indicates more of the covariates less likely influenced the overall population to participate on technology.

Before matching some covariates $(27.8 \%)$ estimated pscores show significant but after matching all covariate pscores show insignificant. This indicates, there was no distribution difference between adopters and non-adopters after the pscores were matched. In agreement, after matching there should be no systematic differences in the distribution of covariates between both groups (Caliendo \& Kopeinig 2008). In the current study, after matching mean standardized bias (SB) reduction ranged from $0.1-9.6 \%$ which was fairly below the critical level of $20 \%$ suggested by Rosenbaum and Rubin (1985). Moreover, very low Pseudo- $R^{2}(0.008)$ after matching agreed with the report of Borga (2011) and Tolemariam (2010), after matching the pseudo- $\mathrm{R}^{2}$ is fairly low implying households do not have much distinct characteristics overall and a good match between treated and non-treated households. Therefore, the current study matching had high degree of covariate balance that shows similar observed characteristics between the adopter and non-adopter groups to use in the estimation procedures.

The average treatment effect due to improved chicken breeds intervention on the outcome variables results show indispensably significant impact on participants. Positive values of ATT difference (adopter value minus non-adopter value) indicate that the participants have been benefited from the intervention. Even though, the t-test didn't show significant on knowledge and skill, both groups show an improvement. This implies that technology intervention benefited both the adopters and non-adopters on knowledge and skill improvement. Adopters were significantly benefited from the technology as compared to non-adopters. Moreover, adopters could able to produce more eggs per layer/year, consumed more eggs/year and got better income per layer/year as compared to non-adopters. In lined with, Dehinenet et al. (2014) reported that dairy technology adopters significantly consumed more milk, sold more milk and can get better income per annum as compared to the nonadopters. Moreover, Tolemariam (2010) reported that the quantity of cotton meal used as feed supplements for sheep fattening brings significant impact on treated households as compared to control households and market oriented impact on number of sheep fattened.

Knowledge and skill improvement t-test between adopters and non-adopters shows insignificant, due to this it was not considered in the sensitivity analysis of this study. In agreement, Hujer et al. (2004) reported that, sensitivity analysis for insignificant ATT effects is not meaningful and therefore not considered. For significant outcome variables the sensitivity analysis p-values show similar significance test as compared to before sensitivity analysis. The upper bound p-values were used to see changes in p-values. As $\Gamma$ (gamma) value increased by 0.5 to $\Gamma=3$, the $p$-values showed significant which was below 0.05 . This indicates, adopters and non-adopters were correctly matched and there were no differences between the two groups (no hidden bias due to an unobserved confounder). Further it indicates that important covariates that affected both participation and outcome variables were considered. According to Keele (2010), p-value is valid if there are no unobserved confounders between the treated and control groups and data are correctly matched with no differences.

In the current study, since the lower bounds Hodges-Lehmman point estimates under underestimated the true treatment effect, upper bound were used. In agreement, Becker and Caliendo (2007) and Keele (2010) 
revealed that the lower bounds estimates under the assumption of true treatment effect were underestimated and less important to be reported. The Hodges-Lehmman point estimates of livelihood changes smaller than the estimated mean difference and shows slightly more robust as $\Gamma$ value of 1.5 before the upper bound brackets zero. If there was no hidden bias, Hodges-Lehmman point estimates was 0.50 , however, as $\Gamma$ value increased more than 1.5, the estimated upper bounds bracket zero that implies there was possible hidden bias due to an unobserved confounder on the livelihood changes. In agreement, Diprete \& Gangl (2004) reported that, if sensitivity analysis gamma value is lowest and encompasses zero, the probability of an unobserved characteristic is relatively high and the estimated impact is therefore sensitive to the existence of unobservable.

\section{Conclusion}

Adopters were significantly benefited from the technology as compared to non-adopters. Adopters could able to produce more eggs per layer/ year, consumed more eggs/year and got 168.65 Birr more income per layer/year as compared to non-adopters. Improved chicken breeds intervention had positive ATE. In sensitivity analysis, Hodges-Lehmman point estimate shows there was possible hidden bias due to an unobserved confounder on the livelihood change. Except livelihood changes, the significant difference of adopters and non-adopters on outcome variables was due to the treatment effect of technology intervention.

\section{Acknowledgments}

The authors would like to thank Addis Ababa University for research grant and respondents, experts and enumerators for their polite cooperation and devoting their time for this study.

\section{References}

AIEI (2013), "Impact evaluation methods", http://go.worldbank.org/J35S3J8B60

Asfaw, S., Shiferaw, B. \& Simtowe, F. (2010), "Does technology adoption promote commercialization? Evidence from chickpea technologies in Ethiopia", www.csae.ox.ac.uk/conferences/2010EDiA/papers/121-Asfaw.pdf

Becker, S. O. \& Caliendo M. 2007. Sensitivity analysis for average treatment effects. The Stata Journal 7, 7183.

Berhanu, K. (2012), "The political economy of agricultural extension in Ethiopia: Economic growth and political control", May 2012, Working Paper 042. www.future-agricultures.org. Borga, F. (2011), "Impact of microfinance services on household income: The case of Digaf Micro Financing Company”, MSc. Thesis, Haramaya University, Ethiopia.

Caliendo, M. \& Kopeinig, S. (2005), "Some practical guidance for the implementation of propensity score matching", Discussion paper series, No. 1588, Germany.

Caliendo, M. \& Kopeinig, S. (2008), "Some practical guidance for the implementation of propensity score matching”, Journal Economic Surveys, 22, 31-72.

Catley, A., Burns, J., Abebe, D. \& Suji, O. (2008), "Participatory impact assessment: A guide for practitioners", Feinstein International Center, Tufts University.

CSA, (2012), "The Federal Democratic Republic of Ethiopia. Agricultural sample survey 2011/12 [2004 E.C].Vol. II. Report on livestock and livestock characteristics", Addis Ababa, Ethiopia.

Dehejia, R.H. \& Wahba, S. (2002), "Propensity score-matching methods for non experimental causal studies", The Review of Economics and Statistics, 84, 151-161.

Dehinenet, G., Mekonnen, H., Ashenafi, M., Kidoido, M. \& Bleich E. G. (2014), "The impact of dairy technology adoption on small holder dairy farmers' livelihoods in selected zones of Amhara and Oromia National Regional States, Ethiopia”, Global Journal of Agricultural Economics and Econometrics, 2, 104-113.

Diprete, T.A. \& Gangl, M. (2004), "Assessing Bias in the estimation of causal effects: Rosenbaum bounds on matching estimators and instrumental variables estimation with imperfect instruments", Sociological Methodology, 34, 271-310.

Ferede, S., Ayele, G. \& Teklewold, H. (2003), "Impact of technology on household food security in tef and wheat farming systems of Moretna-Jiru Woreda", Ethiopian Agricultural Research Organization (EARO), Research Report No.48.

Gujarati, G. (2004), Basic econometrics. Fourth Edition. The McGraw-Hill Companies.

Hujer, R., Caliendo, M. \& Thomson, S.L. (2004), "New evidence on the effects of job creation schemes in Germany: A matching approach with Threefold Heterogeneity", Research in Economics, 58, 257-302.

Keele, L. (2010), "An overview of rbounds: An R package for Rosenbaum bounds sensitivity analysis with matched data", www.personal.psu.edu/ljk20/rbounds\%20vignette.pdf

Lechner, M. (2002), "Some practical issues in the evaluation of heterogenous labour market programmes by matching methods", Journal of Royal State Society, 165, 59-82. 
Mendola, M. (2007), “Agricultural technology adoption and poverty reduction: A propensity score matching analysis for rural Bangladesh", Food Policy, 32, 372-393.

Mulugeta, T. \& Hundie, B. (2012), "Impacts of adoption of improved wheat technologies on households' food consumption in South Eastern Ethiopia”, Selected Poster prepared for presentation at the International Association of Agricultural Economists Triennial Conference, Foz do Iguaçu, Brazil, 18-24 August, 2012.

OBoFED (2008), "Socio-economic profile of Oromia National Regional State", www.pcdp.gov.et/Oromiya\%20Regional\%20Profile.pdf .

Pradhan, M. \& Rawlings, L.B. (2002), "The impact and targeting of social infrastructure investments: Lessons from the Nicaraguan Social Fund", The World Bank Economic Review, 16, 275-295.

Rosenbaum, P. R. \& Rubin, D. B., (1983), "The central role of the propensity score in observational studies for causal effects", Biometrika, 70, 41-55.

Rosenbaum, P. R. 2002. Observational Studies. Springer, $2^{\text {nd }}$ Edt., New York, USA.

Rosenbaum, P.R. \& Rubin, D.B. (1985), "Constructing a control group using multivariate matched sampling methods that incorporate the propensity score", American Statistical Association, 39, 33-38.

Sanchez, P.A., Denning, G.L. \& Nziguheba, G. (2009), "The African green revolution moves forward", Food Security, 1, 37-44.

SAS, (2002), "Statistical Analysis System", version 9, Institute, Inc., Cary, NC, USA.

STATA, (2012), "STATA statistical software", STATA Corporation, version 12.0, Lakeway Drive College Station, Texas, USA.

Tolemariam, A. (2010), "Impact assessment of input and output market development interventions by IPMS Project: The case of Gomma Woreda, Jimma Zone”, MSc Thesis, Haramaya University, Ethiopia.

Wanyama, J. M., Nyambati, E. M., Mose, L. O, Mutoko, C. M, Wanyonyi ,W. M., Wanjekeche, E. \& Rono, S. C. (2010), "Assessing impact of soil management technologies on smallholder farmers' livelihoods in North Western Kenya", African Journal of Agricultural Research, 5, 2899-2908.

Wooldridge, M.J. (2002), "Econometric analysis of cross section and panel data", The MIT Press, Cambridge, Massachusetts London, England.

Wu, H., Ding, S., Pandey, S. \& Tao, D. (2010), “Assessing the impact of agricultural technology adoption on farmers' well-being using propensity score matching analysis in rural China", Asian Economic Journal, 24,141-160. 
The IISTE is a pioneer in the Open-Access hosting service and academic event management. The aim of the firm is Accelerating Global Knowledge Sharing.

More information about the firm can be found on the homepage:

http://www.iiste.org

\section{CALL FOR JOURNAL PAPERS}

There are more than 30 peer-reviewed academic journals hosted under the hosting platform.

Prospective authors of journals can find the submission instruction on the following page: http://www.iiste.org/journals/ All the journals articles are available online to the readers all over the world without financial, legal, or technical barriers other than those inseparable from gaining access to the internet itself. Paper version of the journals is also available upon request of readers and authors.

\section{MORE RESOURCES}

Book publication information: http://www.iiste.org/book/

Academic conference: http://www.iiste.org/conference/upcoming-conferences-call-for-paper/

\section{IISTE Knowledge Sharing Partners}

EBSCO, Index Copernicus, Ulrich's Periodicals Directory, JournalTOCS, PKP Open Archives Harvester, Bielefeld Academic Search Engine, Elektronische Zeitschriftenbibliothek EZB, Open J-Gate, OCLC WorldCat, Universe Digtial Library, NewJour, Google Scholar

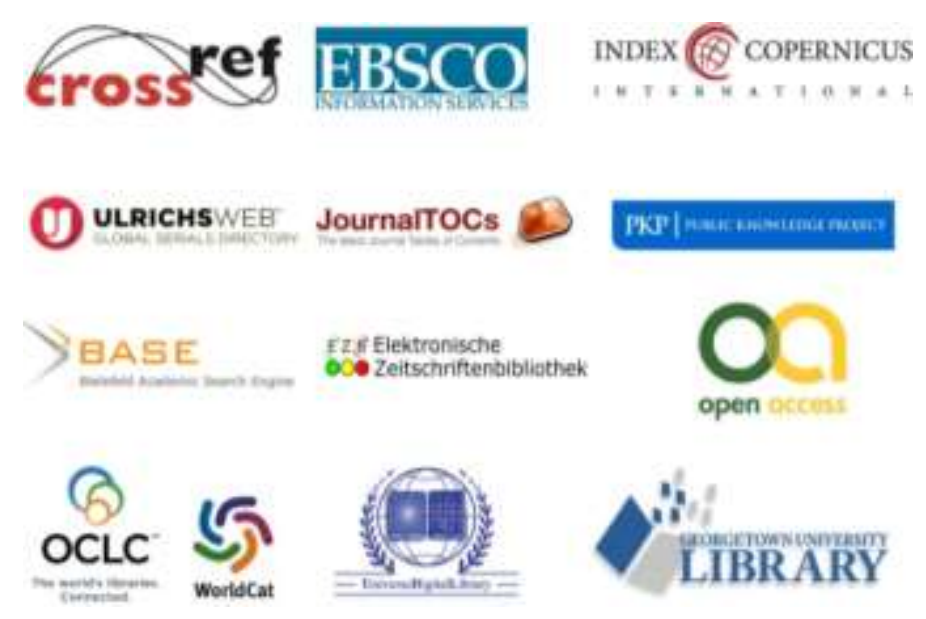

